\title{
Research Article \\ Source Term Analysis of the Irradiated Graphite in the Core of HTR-10
}

\author{
Xuegang Liu, Xin Huang, Feng Xie, Fuming Jia, Xiaogui Feng, and Hong Li \\ Institute of Nuclear and New Energy Technology, Collaborative Innovation Center of Advanced Nuclear Energy Technology, \\ Key Laboratory of Advanced Reactor Engineering and Safety of Ministry of Education, Tsinghua University, \\ Beijing 100084, China \\ Correspondence should be addressed to Feng Xie; fxie@tsinghua.edu.cn
}

Received 31 December 2016; Accepted 20 March 2017; Published 6 April 2017

Academic Editor: Robert Morris

Copyright (C) 2017 Xuegang Liu et al. This is an open access article distributed under the Creative Commons Attribution License, which permits unrestricted use, distribution, and reproduction in any medium, provided the original work is properly cited.

\begin{abstract}
The high temperature gas-cooled reactor (HTGR) has potential utilization due to its featured characteristics such as inherent safety and wide diversity of utilization. One distinct difference between HTGR and traditional pressurized water reactor (PWR) is the large inventory of graphite in the core acting as reflector, moderator, or structure materials. Some radionuclides will be generated in graphite during the period of irradiation, which play significant roles in reactor safety, environmental release, waste disposal, and so forth. Based on the actual operation of the $10 \mathrm{MW}$ pebble bed high temperature gas-cooled reactor (HTR-10) in Tsinghua University, China, an experimental study on source term analysis of the irradiated graphite has been done. An irradiated graphite sphere was randomly collected from the core of HTR-10 as sample in this study. This paper focuses on the analytical procedure and the establishment of the analytical methodology, including the sample collection, graphite sample preparation, and analytical parameters. The results reveal that the Co-60, Cs-137, Eu-152, and Eu-154 are the major $\gamma$ contributors, while $\mathrm{H}-3$ and $\mathrm{C}-14$ are the dominating $\beta$ emitting nuclides in postirradiation graphite material of HTR-10. The distribution profiles of the above four nuclides are also presented.
\end{abstract}

\section{Introduction}

The high temperature gas-cooled reactor (HTGR) has some remarkable advantages, such as inherent safety, higher power efficiency, and wide diversity of heat utilization [1]. Nowadays HTGR is being accepted as one of the most promising nuclear reactors in the future nuclear market. However, the actual development of HTGR still highly relies on the comprehensive understanding of the philosophy of HTGR from all aspects. The source term of the radionuclides resulting from the HTGR operation plays significant roles in reactor safety, environmental release, waste management, and disposal. HTGR features its huge inventory of nuclear graphite in the HTGR core acting as reflector, moderator, or structure materials. The contaminated graphite becomes a special kind of radioactive waste, which is completely different from that in traditional pressurized water reactor (PWR). With the growing application of HTGR, the source term analysis of the irradiated graphite in the HTGR core has been highlighted.
While the nuclear grade graphite has excellent chemical, structural, and neutronic properties for HTGR utilization [2], the utilization of graphite in core leads to the generation of many types of radioactive nuclides in the graphite material. Theoretically, the graphite can retain radionuclides such as $\mathrm{H}$ 3 , C-14, and Cl-36, corrosion/activation products (Co-57, Co60, Mn-54, Ni-59, Ni-63, Na-22, etc.), fission products (Cs134, Cs-137, Sr-90, Eu-152, Ce-144, etc.), and a small amount of uranium and transmutation elements $(\mathrm{Pu}-238, \mathrm{Pu}-239, \mathrm{Am}-$ 241, Am-243, etc.). Some of these radionuclides arise from the activation of impurities which were integral with the original graphite components. The other radionuclides come from offsite locations of the core and migrate to the graphite carried around the circuit in the coolant gas [3, 4]. Practically, the radionuclides in graphite will vary greatly with graphite quality, reactor operating history, fuel element performance, and so forth. An examination by Fachinger et al. [5] indicated that the main $\gamma$ nuclides in the carbon dust in AVR pipe components were Co-60, Cs-137, and Eu-154. Wenzel et al. 


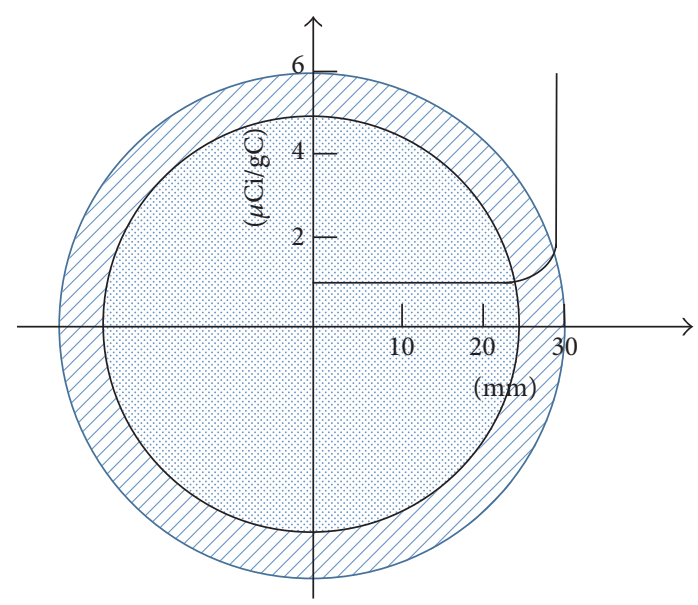

FIgURE 1: C-14 profile in a spent AVR sphere.

[6] determined the C-14 in the graphite matrix of spent AVR fuel element and agreed with the C-14 profile in a spent AVR sphere as published in a previous literature [7] (see Figure 1). Some other literatures [8-10] have introduced the progress of fundamental studies on the behaviors of $\mathrm{H}-3$, Cs, or I in the HTGR system. Besides, some research results on irradiated graphite material used in British Magnox reactors are also useful as [11-13].

In China, a high temperature gas-cooled reactor pebble bed module (HTR-PM) demonstration power plant is under construction in Shandong Province [14]. The reality needs deeper understanding on the characterization of the irradiated graphite material in such type of HTGR. Thanks to the construction and operation of HTR-10, a $10 \mathrm{MW}$ test reactor of the same type, some genuine graphite materials are available and suitable for the above research. A project was proposed with the purpose of mastering the irradiated graphite in pebble bed HTGR, in which the HTR-10 was chosen as a reference reactor. As part of a whole project, this paper will focus on the sample preparation, analytical procedure, and methodology. Some postirradiation graphite sphere are discharged from the reactor core. Samples are collected at different positions of spherical radius, prepared, and measured with different analytical devices, that is, the multi-channel $\gamma$ counter, liquid scintillation counter, and total $\alpha / \beta$ counter. The analytical results are presented.

\section{HTR-10 and Irradiated Graphite Element}

The $10 \mathrm{MW}$ high temperature gas-cooled test reactor (HTR10) was constructed in the late 1990s and realized the first criticality in December 2000. In 2003, HTR-10 firstly succeeded in connecting to the grid with full design capacity. Since then, a number of experiments have been done based on the reactor. Being exposed to the radiation resulted from the above operations, the graphite materials in the core of HTR-10 have been good test subjects for the source term analysis.
The core of HTR-10 is designed to hold large amount of spherical fuel elements, which are $60 \mathrm{~mm}$ in diameter and contain about 12000 of TRISO-coated fuel particles homogeneously distributed in graphite matrix. Before the fueling of the spherical fuel elements, the core was piled with graphite spheres of the same size. During the first starting period, graphite spheres were replaced by spherical fuel elements to reach criticality. When the reactor is in a steady state operation, a fuel handling system makes provision for online refueling by allowing fuel sphere circulation. Considering the behaviors of the graphite sphere, we regard them as the most ideal ones for source term analysis due to the following reasons. (1) Graphite spheres were exposed to the genuine radiation of HTR-10, with almost the same neutron flux and energy spectrum. (2) Materials and manufacturer of the graphite spheres are the same as fuel elements, making them good alternatives to study the properties of graphite matrix in irradiated fuel elements without high radiation from fuel particles. (3) Due to the probabilistic release, it is possible to have a series of graphite spheres with different exposure in the core. Some of them might be staying even longer than fuel elements. (4) Controlled by the fuel handling system, graphite spheres can be discharged from the core or reloaded to the core for higher exposure. All operations can be handled very easily without any negative impact on safe operation of the reactor. But, on the other hand, it should be noted that the probability distribution of staying time in the core makes it difficult to know the exposure history of a specific graphite sphere. In this paper, a postirradiation graphite sphere was collected from the storage tank. We do not know how long it stayed in the core and total exposure it received.

\section{Experimental Works}

Figure 2 shows the experimental program. The whole analysis procedure consists of six major steps. After a prompt measurement on mass, the surface dose rate, and $\gamma$ multichannel spectrum (Step 1), the selected graphite sphere was fixed in a drilling machine. A hollow drilling tool with $9 \mathrm{~mm}$ inner diameter was used to drill a penetrating hole through the center of the sphere. A cylindrical graphite sample was prepared in Step 2 (see Figures 3 and 4). To learn the source term of samples in different radius location, the cylindrical graphite was then fixed in a grinder machine. A series of graphite powder samples were prepared in Step 3. Each powder sample which represents the component of graphite in a specific radius was spread on a stainless steel disk to form a flat circular sample with $40 \mathrm{~mm}$ diameter. The flat circular sample was then analyzed with multichannel $\gamma$ detector and total $\alpha / \beta$ analyzer (Step 4). The graphite sample on the stainless steel disk was then put into a combustion vessel full with oxygen. The gas $\left(\mathrm{CO}_{2}\right.$ and water vapour $)$ was adsorbed with $\mathrm{NaOH}$ solution. The purpose of Step 5 is to convert C-14 and $\mathrm{H}-3$ in the solid graphite into a solution for consequential analysis. In Step 6, the above aqueous sample was analyzed with titration to measure the total carbon in solution and liquid scintillation counter (LSC) to measure the activity of C-14 and H-3. 


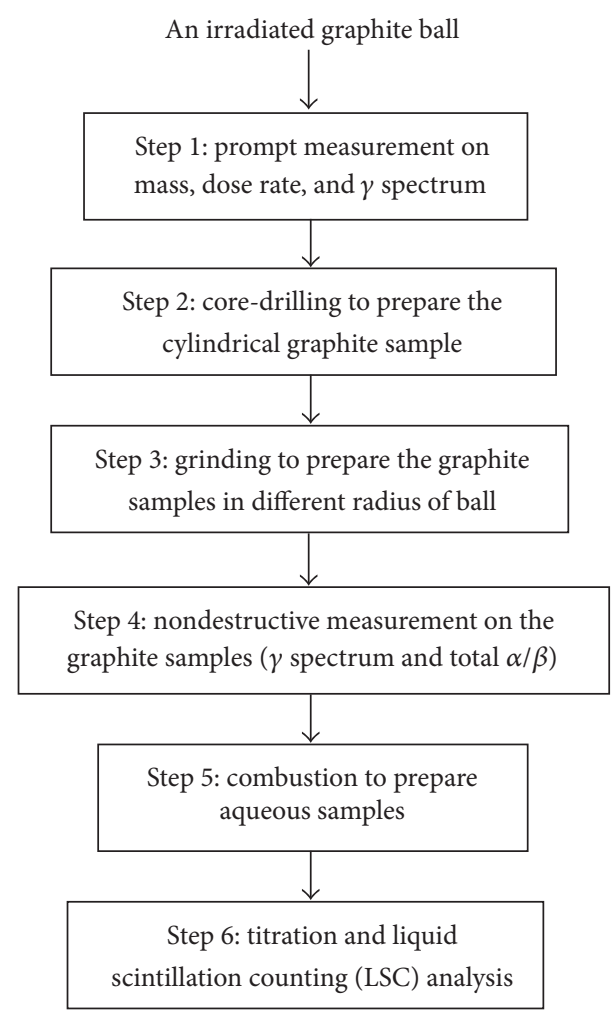

FIGURE 2: The experimental program on source term analysis of an irradiated graphite sphere.

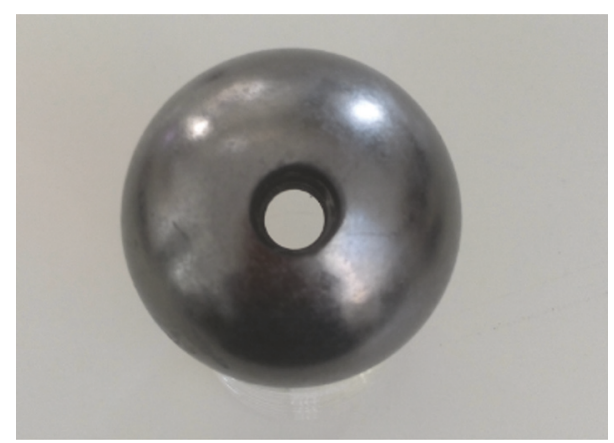

FIGURE 3: The graphite sphere with a penetrating hole after drilling.

\section{Results and Discussions}

4.1. The Measurement of the Irradiated Graphite Sphere. The selected postirradiation graphite sphere was weighed as $208.82 \mathrm{~g}$. The dose rate at the very surface of the sphere was about $25.2 \pm 0.5 \mu \mathrm{Sv} / \mathrm{h}$. The multichannel $\gamma$ spectrum is shown in Figure 5, which exhibits the most distinct four nuclides: Co-60, Eu-152, Eu-154, and Cs-137. Although, due to the special shape of the graphite sphere, it is difficult to calibrate the detective efficiency of each peak of spectrum, the results are very useful to evaluate the external exposure of the irradiated graphite materials.

4.2. Combustion of Graphite Powders. In order to measure the C-14 and H-3 with LSC, a combustion process was developed
TABLE 1: Distribution ratios of nuclide after graphite combustion.

\begin{tabular}{|c|c|c|c|}
\hline \multirow[b]{2}{*}{ Nuclides } & \multicolumn{3}{|c|}{ Distribution ratio (\%) } \\
\hline & In residue & $\begin{array}{c}\text { In } \mathrm{NaOH} \text { aqueous } \\
\text { solution }\end{array}$ & In off-gas \\
\hline H-3 & $<1 \%$ & $\sim 95 \%$ & $\sim 5 \%$ \\
\hline C-12 & $<1 \%$ & $>99 \%$ & $<1 \%$ \\
\hline C-14 & $<1 \%$ & $>99 \%$ & $<1 \%$ \\
\hline Co-60 & $\sim 100 \%$ & BKG & BKG \\
\hline Cs-137 & $\sim 100 \%$ & BKG & BKG \\
\hline $\mathrm{Eu}-152$ & $\sim 100 \%$ & BKG & BKG \\
\hline $\mathrm{Eu}-154$ & $\sim 100 \%$ & BKG & BKG \\
\hline
\end{tabular}

BKG: background.

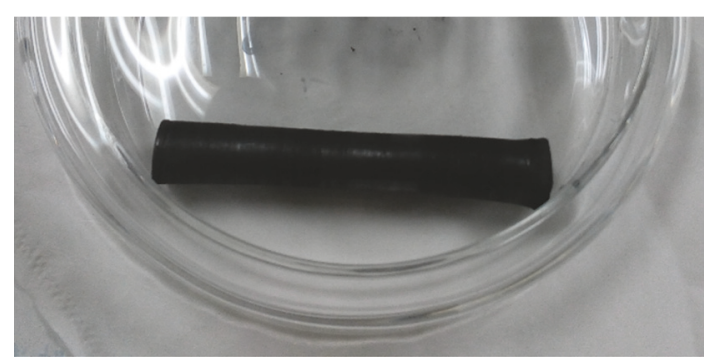

FIGURE 4: The cylindrical graphite sample prepared after drilling.

to convert the graphite powder into the aqueous solution. The powder sample was firstly weighed and put into the crucible of an Oxygen Combustion Apparatus [15] (see Figure 6). After the oxygen inflation and ignition, most graphite powder was burned except for a very small amount of residues left on the crucible bottom. The gasified substance may be absorbed by $\mathrm{NaOH}$ solution in the beaker or exist in the gas. When the vent valve was released slowly and carefully, the off-gas in the vessel can pass through a series of adsorber bottles to trap all concerned components for analysis. As a result, all radionuclides originally in the graphite powder will be transferred to three possible destinations as solid residue, $\mathrm{NaOH}$ solution, and the off-gas adsorption solution.

4.2.1. Combustion Conditions. No doubt, the final destination of each nuclide relies on the combustion conditions to some extent. A stable and quantitative distribution among the flows is desirable for our task. Through a series of systematic experiments and optimization, the combustion conditions were finally chosen as follows: (1) 0.1 to 0.2 gram of graphite powders in the crucible; (2) $10 \mathrm{~mL}$ of $\mathrm{NaOH}$ with the concentration of 3 to $4 \mathrm{~mol} / \mathrm{L}$; (3) $>20$ atm of oxygen in the vessel; (4) >20 min of ageing after combustion with some gentle shaking.

4.2.2. Behaviors of the Certain Nuclides in Combustion. The stable carbon and C-14 were measured by titration and LSC, respectively. The H-3 was also measured by LSC, while $\gamma$ emitting nuclides were detected by multichannel $\gamma$ detector. The distribution ratios of the above nuclides are shown in Table 1 . 


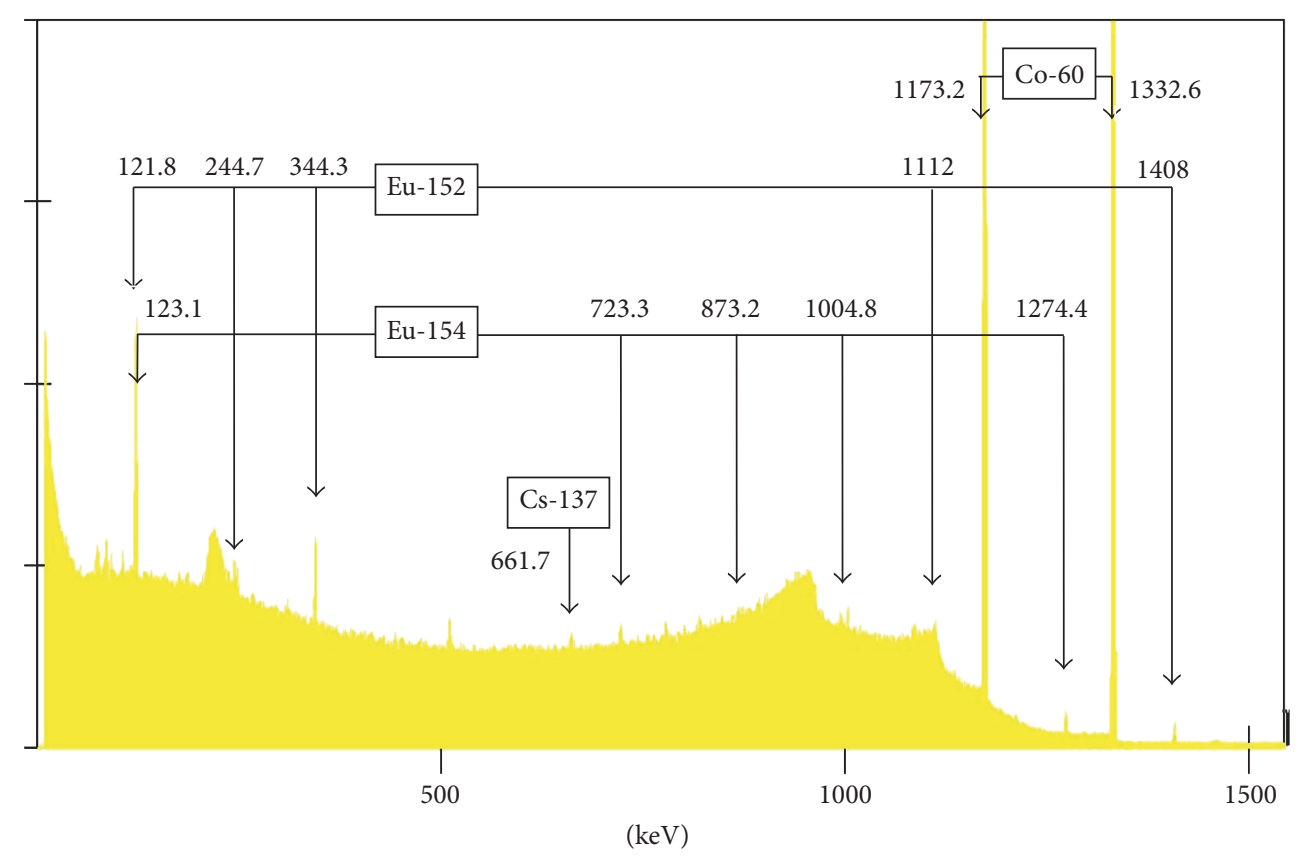

FIGURE 5: The multichannel $\gamma$ spectrum of the irradiated graphite sphere.
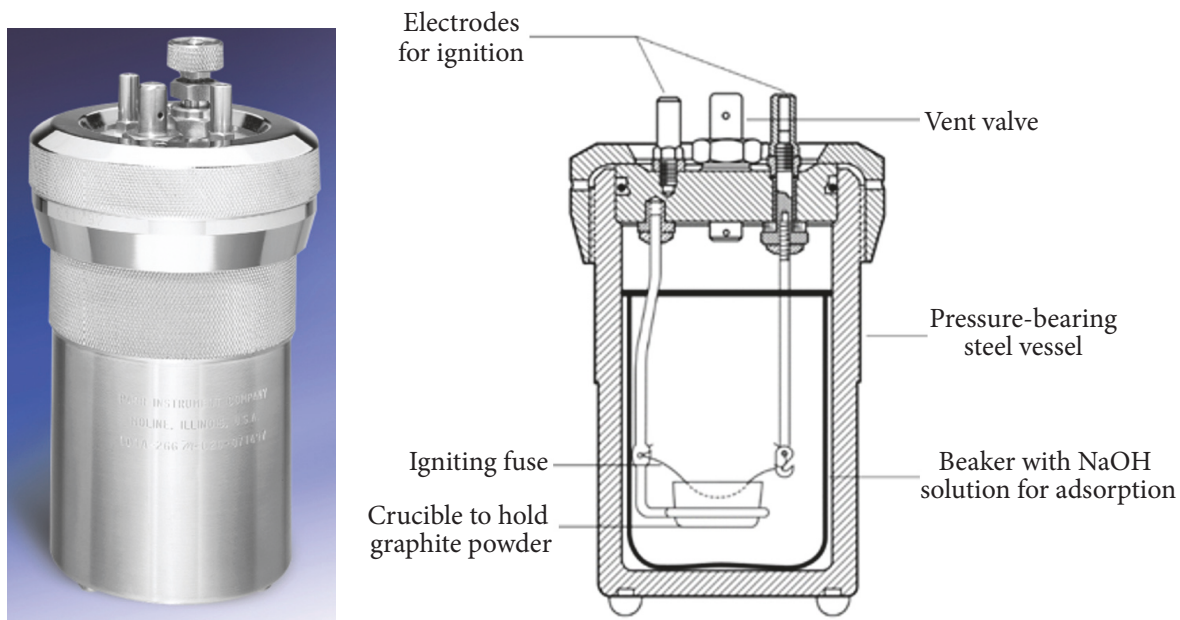

FIGURE 6: The oxygen combustion apparatus and structure schematic.

Because all $\gamma$ emitting nuclides in graphite belong to metal elements, they will remain in the crucible after combustion. As an evidence, Figure 7 shows the comparison of $\gamma$ spectrums between $\mathrm{NaOH}$ aqueous solution and the residual powder. Therefore, no disturbance from $\gamma$ radionuclides needs to be considered in the LSC analysis on $\mathrm{NaOH}$ solution samples. Almost all carbon, both stable and radioactive, was found to be adsorbed in $\mathrm{NaOH}$ solution. Because a small portion of $\mathrm{H}-3$ was lost in the off-gas, the analytical result of $\mathrm{H}-3$ in $\mathrm{NaOH}$ solution will be lower than the fact. However, such kind of deviation is acceptable in the case of source term analysis.

\subsection{Distribution Profile of Radionuclides in the Graphite Sphere}

4.3.1. The Distribution of $\gamma$ Emitting Nuclides. Figures 8 and 9 show the distribution profiles of Co-60/Cs-137 and Eu$152 / \mathrm{Eu}-154$ in the graphite sphere, respectively.

Among all $\gamma$ emitting nuclides, Co-60 has the highest activity in the irradiated graphite sphere. The distribution of Co-60 implies a much higher activity on the spherical surface than the interior. And the activities of Co-60 inside of the sphere have no distinct dependence on the distance to the center. According to the present study, the distributions of 


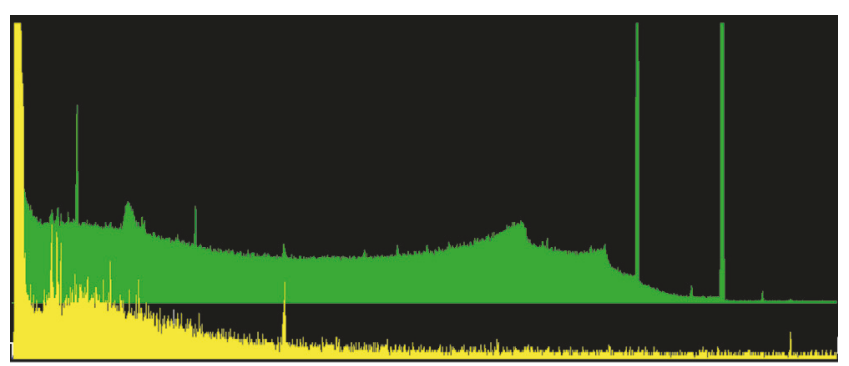

Figure 7: The comparison of $\gamma$ spectrums between $\mathrm{NaOH}$ aqueous solution and graphite residue (the green for the residual powder, the yellow for the $\mathrm{NaOH}$ solution).

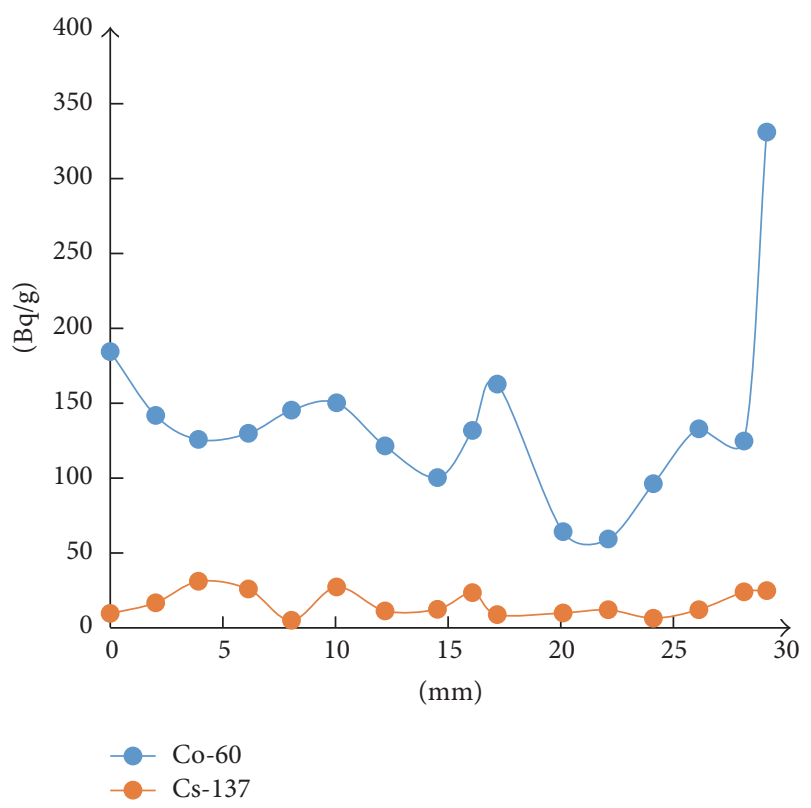

FIGURE 8: Distribution profiles of Co-60 and Cs-137 activities at different spherical radii in the selected graphite sphere.

Cs-137, Eu-152, and Eu-154 in the sphere showed weak or no correlative effect on the radius. The different distribution between Co-60 and fission products (Cs-137, Eu-152, and Eu154) may be explained by their generation mechanisms. The Co-60 inside of the graphite sphere might come from the neutron activation of the impurity (mainly Co-59), while the surface might be contaminated by the dusts in the primary coolant circuit. For Cs-137, Eu-152, and Eu-154, the mechanism is supposed to be neutron activation of the impurity (trace of uranium, possibly). Certainly, much more work has to be done to investigate the generation mechanisms of the above nuclides.

4.3.2. The Distribution of $\beta$ Emitting Nuclides. Figure 10 shows the total $\beta$ count per gram of graphite at different radial locations. Figure 11 shows the dependence of $\mathrm{H}-3$ and C-14 specific activity on the distance to the spherical center. Both figures indicate that $\beta$ emitting nuclides, $\mathrm{H}-3$ and $\mathrm{C}-14$, are uniformly distributed in the graphite sphere.

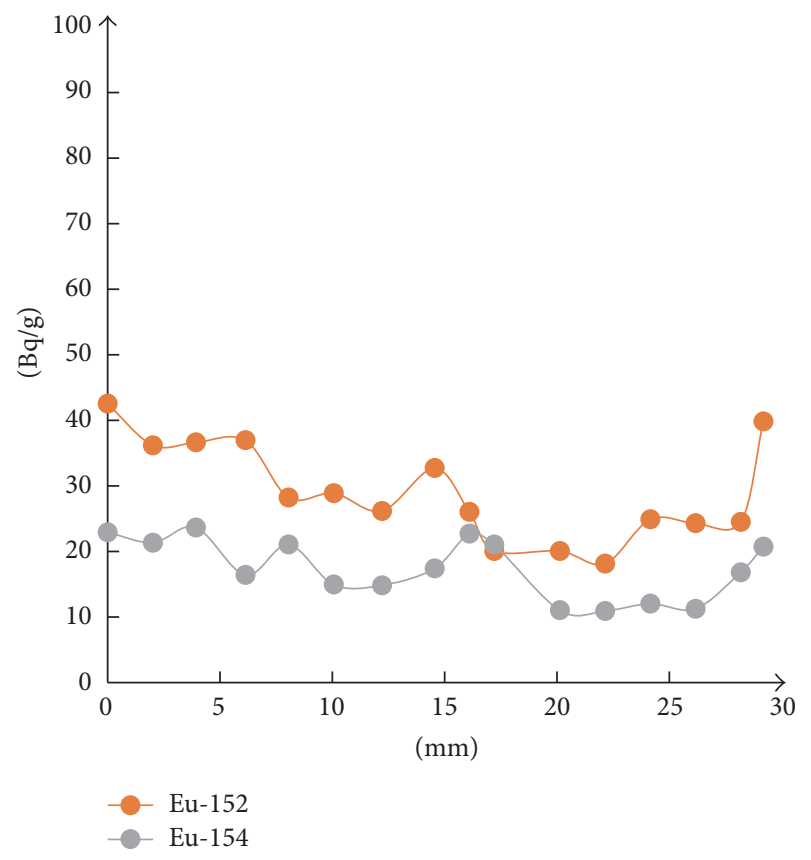

FIGURE 9: Distribution profiles of Eu-152 and Eu-154 activities at different spherical radii in the selected graphite sphere.

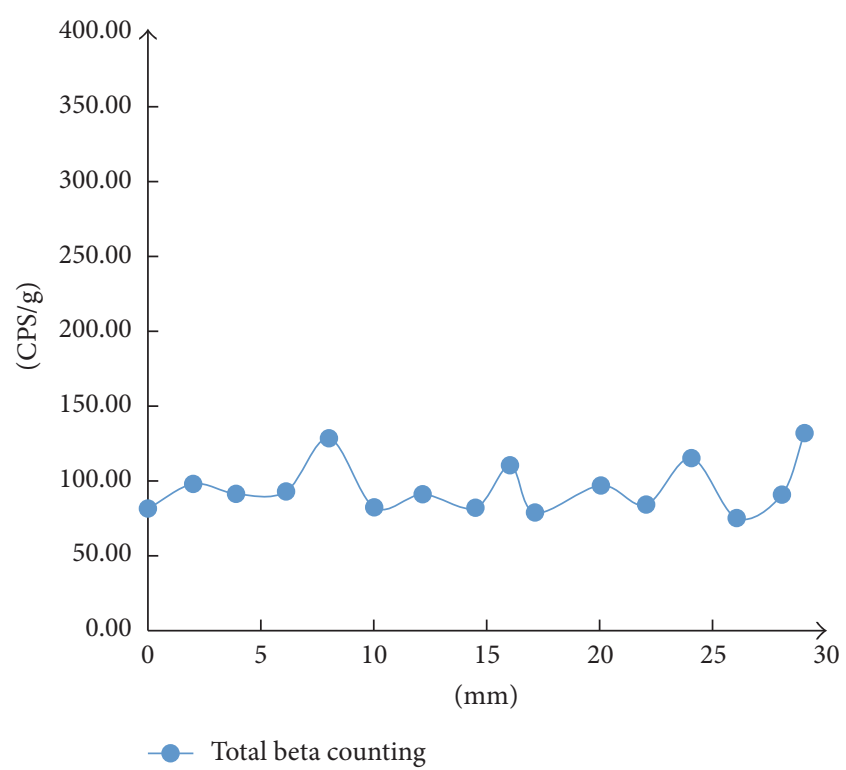

FIGURE 10: Total $\beta$ count per gram of graphite at different spherical radii.

\section{Conclusion and Remarks}

Based on operation of HTR-10, an investigation on the source term of irradiated graphite was conducted. Some initial work has been completed to establish an experimental analysis procedure to measure the radionuclides in the irradiated graphite sphere. In this paper, the procedure was used successfully to analyze one randomly selected irradiated graphite sphere 


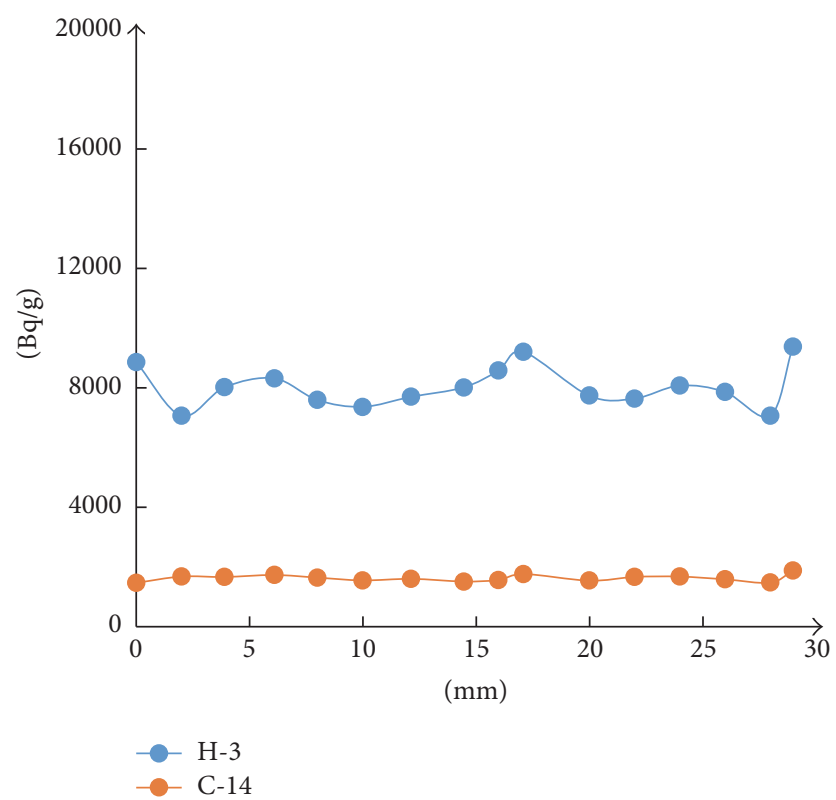

Figure 11: Profile of H-3 and C-14 specific activity at different spherical radii.

discharged from HTR-10. The results show that Co-60, Cs137, Eu-152, and Eu-154 are major contributors of $\gamma$ radiation. $\mathrm{H}-3$ and $\mathrm{C}-14$ are the most important $\beta$ emitting nuclides in graphite. Except for Co-60, which indicated a sharp rise on the surface, the distributions of other radionuclides were almost uniform from the outer surface to the spherical center.

It shall be noted that this paper is focusing on the analytical procedure rather than obtaining a result or predicting the mechanism of radionuclides generation or immigration. Due to the uncertainty of graphite sphere sampling, any one of them is incapable of representing all graphite spheres in the core. To understand the source term, analysis of a large number of irradiated spheres seems essential.

\section{Conflicts of Interest}

The authors declare that they have no conflicts of interest regarding the publication of this paper.

\section{Acknowledgments}

This work was supported by the National Natural Science Foundation of China (no. 11575099), the National Science and Technology Major Project of the Ministry of Science and Technology of China (Grant no. 2011ZX06901), and the Beijing Natural Science Foundation (no. 2163051).

\section{References}

[1] H. Sekimoto, S. Shiozawa, Y. Tsuchie et al., "Perspective of HTGR and its commercial development," in Proceedings of the International Seminar, IAEA-SR-218/219, pp. P322-P327, Cairo, Egypt, May 2001.
[2] T. D. Burchell, "Graphite: properties and characteristics," Comprehensive Nuclear Materials, vol. 2, pp. 285-305, 2012.

[3] A. J. Wickham, "UK Nuclear Graphite Decommissioning," 2008.

[4] A. N. Jones and B. J. Marsden, "Review of the characterisation of nuclear graphites in UK reactors scheduled for decommissioning," Tech. Rep. IAEA-TECDOC-1647, 2010.

[5] J. Fachinger, A. Kummer, G. Caspary et al., "Examination of dust in AVR pipe components," in Proceedings of the 4th International Topical Meeting on High Temperature Reactor Technology (HTR '08), pp. 591-602, Washington, DC, USA, October 2008.

[6] U. Wenzel, D. Herz, and P. Schmidt, "Determination of ${ }^{14} \mathrm{C}$ in spent HTGR fuel elements," Journal of Radioanalytical Chemistry, vol. 53, no. 1-2, pp. 7-15, 1979.

[7] P. C. Schmidt, "Alternativen zur Verminderung der C-14Emission bei der Wiederaufbereitung von HTR-Brennelementen," KFA-Bericht Jül-1567, und Diss. RWTH Aachen, 1975.

[8] H. Li, C. Yang, C. Fang, and B. Feng, "Experimental study on the adsorption and desorption of tritium in the graphite materials for HTR-PM," Progress in Nuclear Energy, vol. 85, pp. 676-681, 2015.

[9] L. M. Carter, J. D. Brockman, J. D. Robertson, and S. K. Loyalka, "Diffusion of cesium and iodine in compressed IG-110 graphite compacts," Journal of Nuclear Materials, vol. 476, pp. 30-35, 2016.

[10] K. L. Walton, T. K. Ghosh, D. S. Viswanath, S. K. Loyalka, and R. V. Tompson, "Adsorption of iodine on graphite in High Temperature Gas-Cooled Reactor systems: a review," Progress in Nuclear Energy, vol. 73, pp. 21-50, 2014.

[11] M. P. Metcalfe and R. W. Mills, "Radiocarbon mass balance for a Magnox nuclear power station," Annals of Nuclear Energy, vol. 75, pp. 665-671, 2015.

[12] R. W. Mills, Z. Riaz, and A. W. Banford, "Nuclear data issues in the calculation of C-14 and Cl-36 in irradiated graphite," in Proceedings of the European Nuclear Conference (ENC '12), Manchester, UK, 2012.

[13] T. Lansdell and M. Newland, "Magnox reactor graphite characterisation stage 2-final active analysis stage," Babcock Report TSG(11)0801, 2012.

[14] Z. Zhang, Y. Dong, F. Li et al., “The Shandong Shidao Bay 200 MWe high-temperature gas-cooled reactor pebble-bed module (HTR-PM) demonstration power plant: an engineering and technological innovation," Engineering, vol. 2, no. 1, pp. 112-118, 2016.

[15] "1108 Oxygen Combustion Vessel Operating Instruction Manual. Parr Instrument Company," http://www.parrinst.com. 


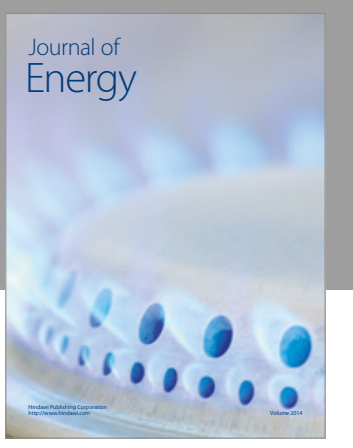

Journal of

Industrial Engineering
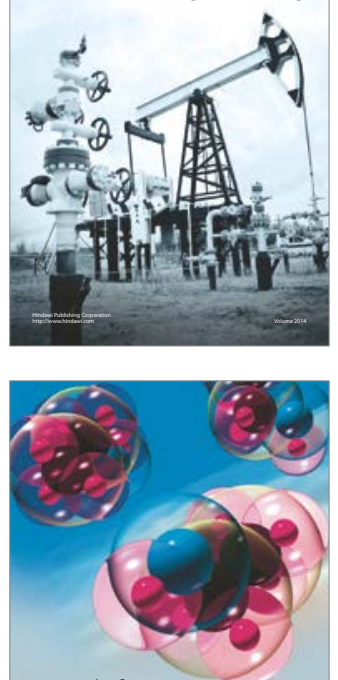

Fuels
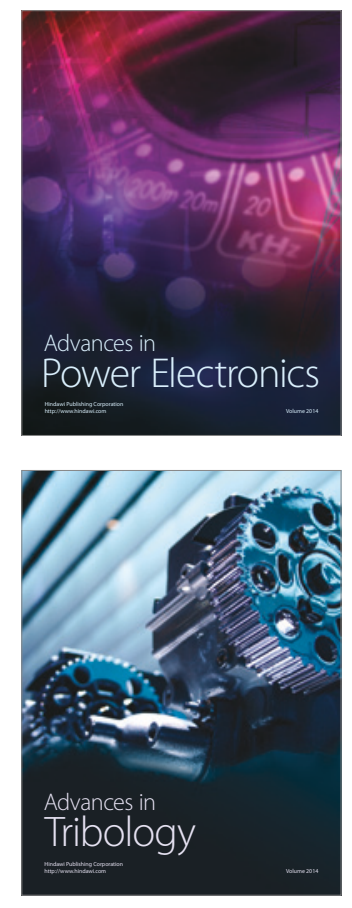
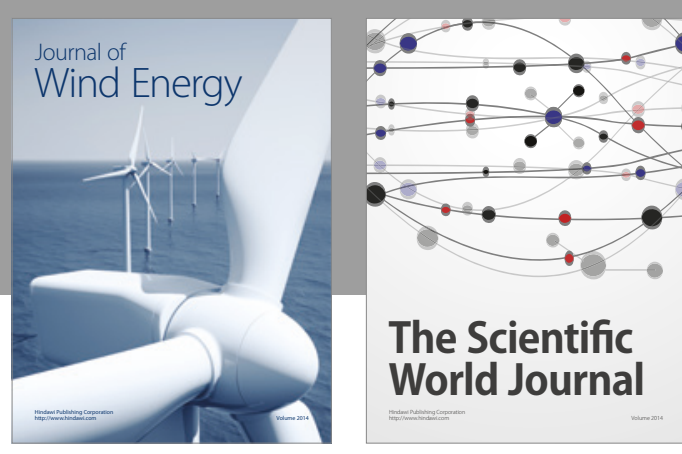

The Scientific World Journal
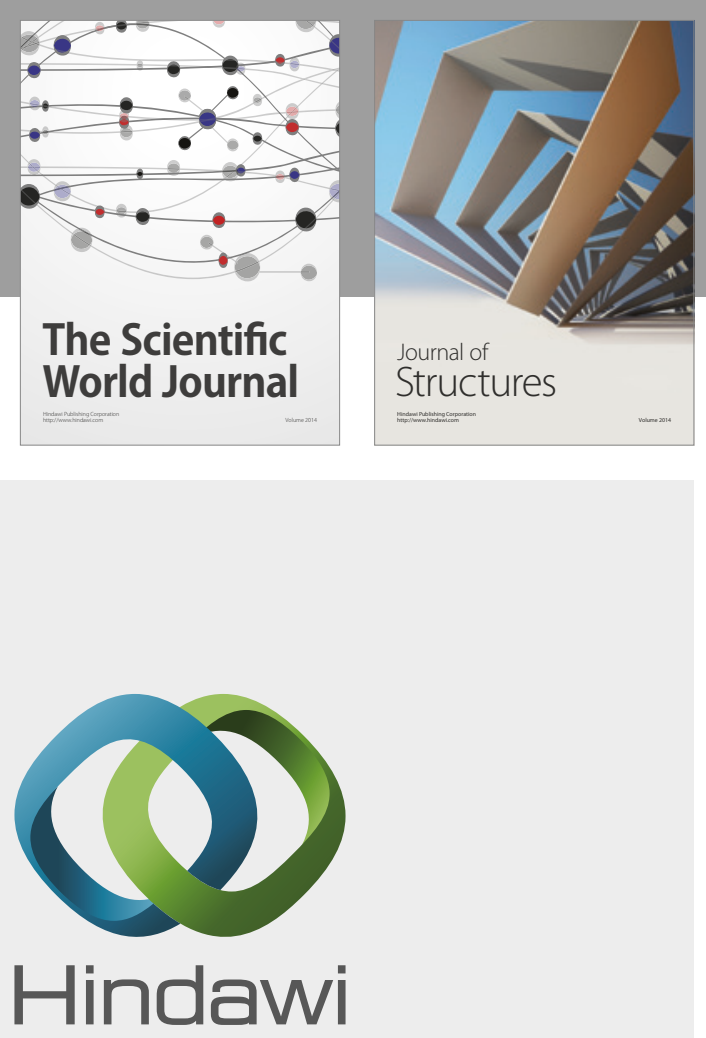

Submit your manuscripts at

https://www.hindawi.com
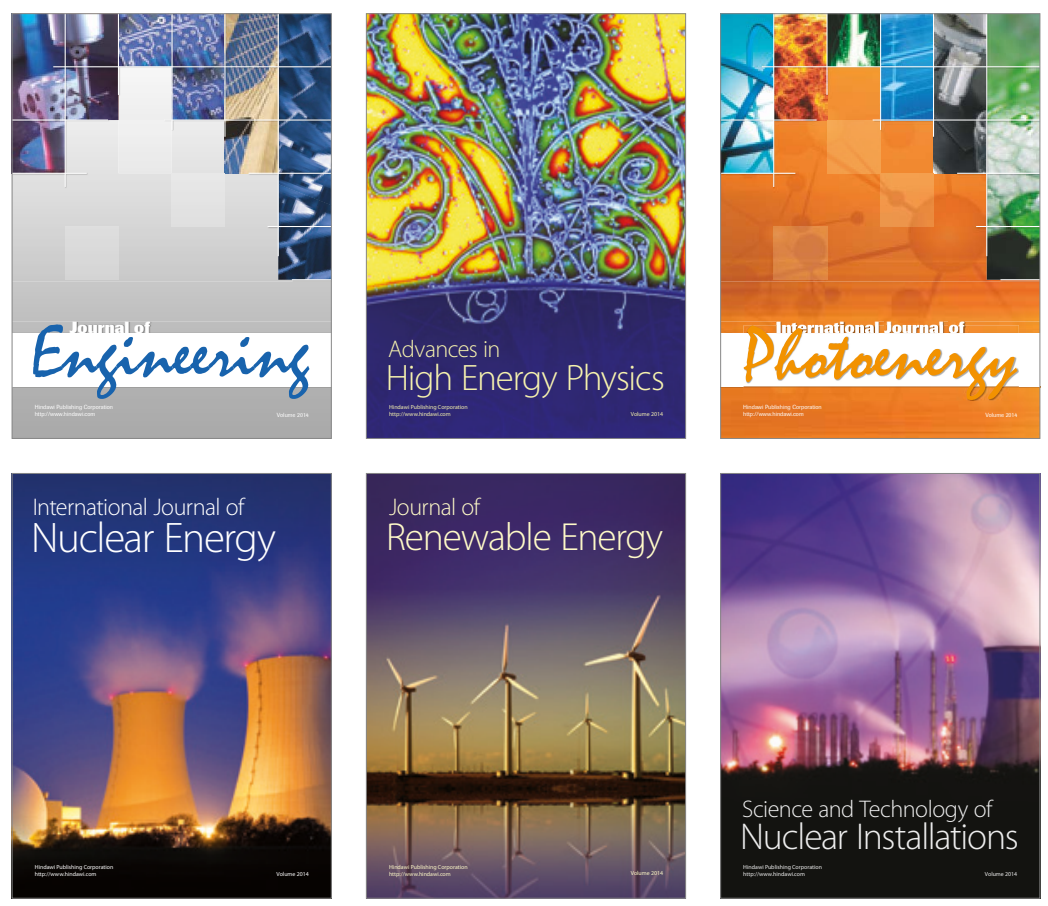

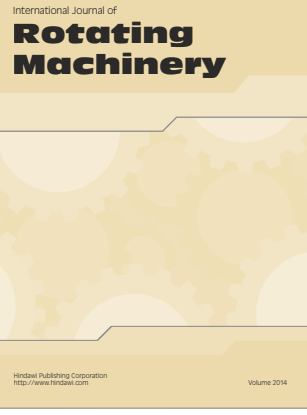

Journal of

Petroleum Engineering

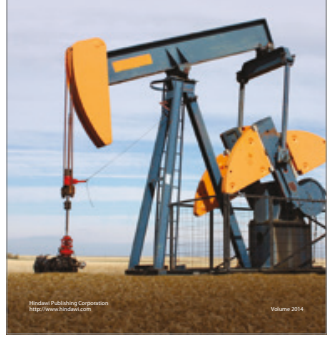

Journal of
Solar Energy
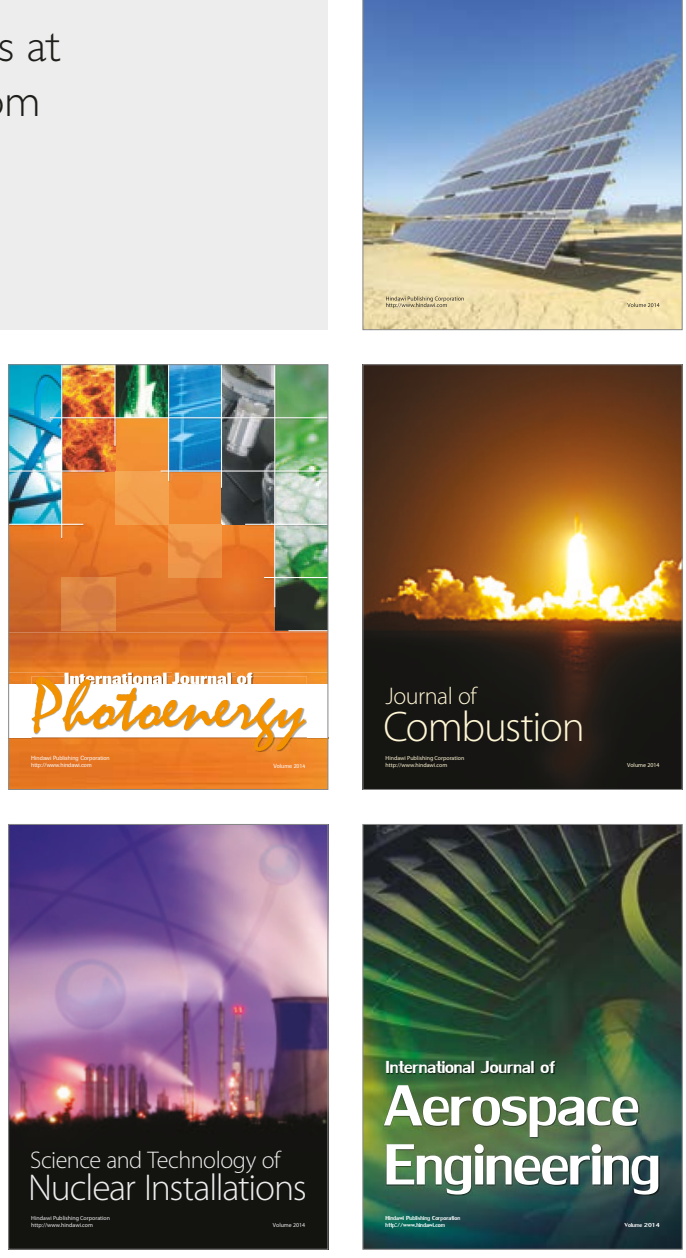